\title{
Do I Need to Operate on That in the Middle of the Night? Development of a Nomogram for the Diagnosis of Severe Acute Cholecystitis
}

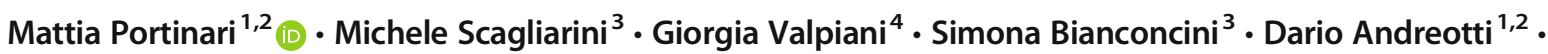 \\ Rocco Stano ${ }^{1,5} \cdot$ Paolo Carcoforo ${ }^{1,2} \cdot$ Savino Occhionorelli ${ }^{1,2,5}$
}

Received: 6 November 2017 / Accepted: 5 February 2018

(C) 2018 The Society for Surgery of the Alimentary Tract

\begin{abstract}
Background Some authors have proposed different predictive factors of severe acute cholecystitis, but generally, the results of risk analyses are expressed as odds ratios, which makes it difficult to apply in the clinical practice of the acute care surgeon. The severe form of acute cholecystitis should include both gangrenous and phlegmonous cholecystitis, due to their severe clinical course, and cholecystectomy should not be delayed. The aim of this study was to create a nomogram to obtain a graphical tool to compute the probability of having a severe acute cholecystitis.

Methods This is a retrospective study on 393 patients who underwent emergency cholecystectomy between January 2010 and December 2015 at the Acute Care Surgery Service of the S. Anna University Hospital of Ferrara, Italy. Patients were classified as having a non-severe acute cholecystitis or a severe acute cholecystitis (i.e., gangrenous and phlegmonous) based on the final pathology report. The baseline characteristics, pre-operative signs, and abdominal ultrasound (US) findings were assessed with a stepwise multivariate logistic regression analysis to predict the risk of severe acute cholecystitis, and a nomogram was created.

Results Age as a continuous variable, WBC count $\geq 12.4 \times 103 / \mu \mathrm{l}, \mathrm{CRP} \geq 9.9 \mathrm{mg} / \mathrm{dl}$, and presence of US thickening of the gallbladder wall were significantly associated with severe acute cholecystitis at final pathology report. A significant interaction between the effect of age and CRP was found. Four risk classes were identified based on the nomogram total points.

Conclusions Patients with a nomogram total point $\geq 74$ should be considered at high risk of severe acute cholecystitis (at 74 total point, sensitivity $=78.5 \%$; specificity $=78.2 \%$; accuracy $=78.3 \%$ ) and this finding could be useful for surgical planning once confirmed in a prospective study comparing the risk score stratification and clinical outcomes.
\end{abstract}

Keywords Acute cholecystitis $\cdot$ Emergency treatment $\cdot$ Multivariate analysis $\cdot$ Retrospective studies $\cdot$ Nomogram

Mattia Portinari

mattia.portinari@unife.it

1 Department of Surgery, S. Anna University Hospital of Ferrara, Via Aldo Moro, 8 | Stanza 23439 (1C2) (Cona), 44124 Ferrara, Italy

2 Department of Morphology, Surgery and Experimental Medicine, University of Ferrara, Ferrara, Italy

3 Department of Statistics, University of Bologna, Bologna, Italy

4 Research Innovation Office, S. Anna University Hospital of Ferrara, Ferrara, Italy

5 Acute Care Surgery Service, S. Anna University Hospital of Ferrara, Ferrara, Italy

\section{Introduction}

Do I need to operate on that in the middle of the night? Any acute care surgeon must answer this question based on the evaluation of the disease process severity and the need to schedule the operation according to the priority of surgical patients visited in the emergency department. The triage is an important process on focusing the resources and to guarantee the proper timing for the treatment. In the emergency department, acute cholecystitis represents an indication for early cholecystectomy within $72 \mathrm{~h}$ after the onset of symptoms; ${ }^{1,2}$ however, the presence of a severe acute cholecystitis may increase the risk of morbidity and mortality and may impose a surgical prioritization in these patients compared to others. 
Of note, it has been suggested that the severe form of acute cholecystitis should include both gangrenous and phlegmonous cholecystitis. ${ }^{3}$ Usually, acute cholecystitis begins with an attack of biliary colic, often in a patient who has had previous attacks, yet the pain persists and localizes in the right upper quadrant. ${ }^{4}$ Fever and an elevation of the white blood cell (WBC) count are classically described in patients with acute cholecystitis, but either or both may be absent. ${ }^{5}$ The C-reactive protein (CRP) level is frequently elevated. ${ }^{6}$ The abdominal ultrasound (US) is the most common imaging study used in diagnosis, and it is usually the first instrumental test because of its ready availability. ${ }^{4}$ The accurate clinical diagnosis of acute inflammation of the gallbladder may often be difficult due to the similarity of symptoms between an attack of biliary colic and acute cholecystitis. ${ }^{7}$ Yokoe et al. have proposed and appraised the diagnostic criteria for acute cholecystitis, but there are some limitations of these criteria. In fact, they have not defined the cutoff of the WBC count and CRP level that can be used for the diagnosis of severe acute cholecystitis, and they have not described factors for the discrimination of non-severe and severe acute cholecystitis. ${ }^{8}$ Some authors have proposed different predictive factors of severe acute cholecystitis, but generally, the results of risk analyses are expressed as odds ratios (ORs), which makes it difficult to apply in the clinical practice of the acute care surgeon. ${ }^{3,7,9-15}$

The aim of this study was to identify predictors for assessing the risk of severe acute cholecystitis (i.e., gangrenous and phlegmonous) and, on the basis of the estimated model, to create a nomogram for obtaining a graphical tool to compute the probability of having a severe acute cholecystitis.

\section{Materials and Methods}

\section{Study Population and Data Collection}

This is a retrospective cohort study on patients operated between January 2010 and December 2015 at the Acute Care Surgery Service of the S. Anna University Hospital of Ferrara, Italy. This study was conducted in accordance with the guidelines described in the statement on strengthening the reporting of observational studies in epidemiology (STROBE). ${ }^{16}$ Patients admitted either through the emergency department or with consultation on the medical service who underwent an emergency cholecystectomy were identified retrospectively from the hospital electronic medical records in which the data were included prospectively. A retrospective analysis was obtained from a database in which patients' data were collected with details of gender, age, diabetes, pre-operative local signs of inflammation (right upper quadrant mass/pain/tenderness, Murphy's sign), pre-operative systemic signs of inflammation (temperature, WBC count, neutrophils count, CRP level), pre-operative abdominal US findings (thickening of the gallbladder wall, pericholecystic fluid, gallbladder enlargement, gallbladder stones), and final pathology report that it is the gold standard for diagnosis of acute cholecystitis. ${ }^{4}$ Due to the aim of this study, the exclusion criterion was the absence in the electronic medical records of at least one data reported above. The abdominal US is the first-line test due to the superiority of this exam in establishing the diagnosis of acute cholecystitis compared to the computed tomography (CT),${ }^{17}$ and only in some patients a CT was performed to evaluate complications of acute cholecystitis. Thus, for the creation of a nomogram, CT findings were excluded.

Surgical specimens were examined at the time of surgery by seven pathologists and, because of the aim of the study, final pathology reports were reviewed and classified according to the pathological criteria reported in a previous study in which the predictive factors of severe acute cholecystitis were evaluated. ${ }^{3}$ Therefore, patients were classified as having a non-severe acute cholecystitis (i.e., acute and chronic cholecystitis with neutrophilic and/or lymphoplasma cellular infiltration of the gallbladder wall) or a severe acute cholecystitis (i.e., gangrenous cholecystitis when a transmural necrosis of the gallbladder wall was present, and phlegmonous cholecystitis when a necrosis that involved a limited part of the layers of the wall was identified) according to the final pathology report.

This study was approved by the Institutional Review Board at the S. Anna University Hospital of Ferrara (Ethical Committee for Human Subject Research study number: 170185). All patients signed a written informed consent. Data collection and analysis were performed in compliance with the Helsinki Declaration of 1975.

\section{Statistical Analysis}

The statistical analysis was performed on 393 out of 516 patients who underwent an emergency cholecystectomy. We randomly split the study population (393 patients) into two groups: one for model derivation ( $75 \%$ of the population295 patients) and the other for model validation (the remaining 25\%-98 patients). No imputation methods were used in analysis. Data are presented as frequencies with percentages, and medians with 25-75th percentiles (interquartile rangeIQR 25-75) depending on the type of data and their distribution. The Shapiro-Wilk test was used to assess the assumption of normality. Differences between proportions from the derivation and validation cohorts were calculated using $\chi 2$ test, and Mann-Whitney $U$ test was used to compare skewed data. A receiver operating characteristic (ROC) curve was used: (1) to investigate the diagnostic accuracy of WBC count and CRP level in predicting the severe acute cholecystitis and (2) to identify the optimal cutoff point of these tests to discriminate 
patients with disease from those without disease. The best cutoff was defined as the titer generating the highest Youden's J statistic, which combines information about sensitivity and specificity into a single value. The model was developed using data solely from a derivation cohort, which included 295 patients. Variables were evaluated by univariate logistic regression analysis, while the model was developed using a stepwise multivariate logistic regression analysis. Variables were selected on the basis of their associations with increased severe acute cholecystitis risk $(p<0.05$; univariate analysis) or known relevance, and they were included in the variable pool for a stepwise regression model. The risk score was calculated using regression coefficients from the final multivariate model. Once a final model was defined, patients were divided into four risk groups according to low, intermediate, high, and very high risk of severe acute cholecystitis. We then used the Cochran-Armitage trending statistic, which modifies the $\chi^{2}$ test to incorporate a suspected ordering, to assess the ability of the risk score system to differentiate lowrisk from high-risk patients in a graded response.

\section{Model Performance Assessment}

To evaluate the performance model, we considered overall performance, calibration, and discrimination. We used the le Cessie-van Houwelingen-Copas test ${ }^{18,19}$ to evaluate the overall goodness of fit. The le Cessie-van Houwelingen-Copas test uses the sum of squared differences of the individual observed and the predicted risks. We assessed model calibration using the calibration graph. "Non-parametric" is a smoothed function of observed events plotted versus predicted probabilities, while "Ideal" is the ideal 45-degree line and the triangles indicate the outcomes for deciles of prediction with their $95 \%$ confidence intervals. ${ }^{20,21} \mathrm{We}$ assessed model discrimination using the concordance $(c)$ statistic which represents the area under the ROC curve (larger values indicate improved discrimination) and defines how well a model or prediction rule can discriminate between patients who do and do not have an event and measures how well a clinical prediction rule correctly ranks patients in order by risk. ${ }^{20}$ Using the $\mathrm{R}$ "rms" package, ${ }^{22,23}$ we obtained a convenient graphical tool (i.e., nomogram) to compute the probability of having a severe acute cholecystitis. Each predictor variable has a corresponding point value based on its position on the top point scale and contribution to the model. A total score is given to each subject by adding up the points. The probability of developing a severe cholecystitis for each subject can be calculated by the total score from the scale presented on the bottom line.

The performance of the algorithm obtained from the derivation cohort was tested on the randomly selected validation cohort (98 patients). In the validation study, conditions, definitions, and measurements were identical to those of the development study.
Significance was considered for values of $p<0.05$. Statistical analysis was performed with IBM SPSS Statistics for Windows, Version 24.0 (IBM Corp. Armonk, NY: IBM Corp.) and R (R CoreTeam 2015 [http://www.R-project. org/]).

\section{Results}

\section{Study Population}

A total of 516 emergency cholecystectomies were performed between January 2010 and December 2015 at the Acute Care Surgery Service. Among these 516 patients, in 94 (18.2\%) patients, CRP evaluation was not carried out in the emergency department or in the medical service, and in $29(5.6 \%)$ patients, abdominal US was not done because the first evaluation was the abdominal CT scan. Thus, these patients were excluded from the study. Three hundred and ninety-three patients were enrolled for this study and the baseline characteristics of patients in the derivation and the validation cohorts are shown in Table 1. There are no differences in the baseline characteristics between the two groups; however, there is a significantly lower percentage of patients with severe acute cholecystitis in the validation cohort compared to the derivation cohort ( 28.6 vs. $39.3 \%$, respectively; $p=0.026$ ).

Table 2 shows the baseline characteristics, pre-operative signs, and pre-operative imaging findings of patients in the derivation cohort according to the final pathology report. Male gender and diabetes prevail in the group of severe acute cholecystitis. Patients with severe acute cholecystitis were older, with a higher WBC count and CRP level, and they had more frequently US thickening of the gallbladder wall and US pericholecystic fluid collection. No differences were found in terms of local signs of inflammation between the two groups.

\section{Predictive Factors of Severe Acute Cholecystitis and Nomogram Development}

Figure 1 shows the ROC curves in the derivation cohort for both WBC count and CRP level as a single predictor of severe acute cholecystitis. The area under the curve (AUC) for WBC count as the single predictor has been calculated as being 0.782 , with a $95 \% \mathrm{CI}$ of $0.730-0.835$; and the ROC curve analysis found the optimal cutoff of WBC count to be $12.4 \times 103 / \mu 1$, to discriminate patients with disease from those without disease. The AUC for CRP level as the single predictor has been calculated as being 0.780 , with a $95 \%$ CI of 0.724-0.835; and the best cutoff of CRP was $9.9 \mathrm{mg} / \mathrm{dl}$.

The univariate logistic regression analysis performed in the derivation cohort showed that male gender, age as a continuous variable, presence of diabetes, temperature $\geq 38^{\circ} \mathrm{C}, \mathrm{WBC}$ 
Table 1 Baseline characteristics and final pathology report of patients in the derivation and the validation cohorts

\begin{tabular}{|c|c|c|c|}
\hline & Derivation cohort $(N=295)$ & Validation cohort $(N=98)$ & $p$ \\
\hline Gender $[N(\%)]$ & & & 0.641 \\
\hline Male & $141(47.8)$ & $50(51.0)$ & \\
\hline Female & $154(52.2)$ & $48(49.0)$ & \\
\hline Age (years) & $68(52-78)$ & $67(52-77)$ & 0.851 \\
\hline Diabetes $[N(\%)]$ & $41(13.9)$ & $13(13.3)$ & 1.000 \\
\hline Temperature $\geq 38^{\circ} \mathrm{C}[N(\%)]$ & $32(10.8)$ & $11(11.2)$ & 1.000 \\
\hline Pre-operative total WBC count $(\times 103 / \mu \mathrm{l})$ & $11.3(8.2-14.8)$ & $11.3(8.2-15.2)$ & 0.868 \\
\hline Pre-operative neutrophils count $(\times 103 / \mu \mathrm{l})$ & $8.9(5.8-12.2)$ & $8.4(5.1-12.6)$ & 0.470 \\
\hline Pre-operative CRP level (mg/dl) & $3.0(0.7-13.9)$ & $3.4(0.6-11.2)$ & 0.524 \\
\hline Pre-operative abdominal ultrasound $[N(\%)]$ & $295(100)$ & $98(100)$ & - \\
\hline Final pathology report $[N(\%)]$ & & & 0.026 \\
\hline Chronic cholecystitis & $117(39.7)$ & $37(37.8)$ & \\
\hline Acute cholecystitis & $62(21.0)$ & $33(33.7)$ & \\
\hline Severe Acute cholecystitis & $116(39.3)$ & 28 (28.6) & \\
\hline
\end{tabular}

$W B C$ white blood cell, $C R P$ C-reactive protein

count $\geq 12.4 \times 103 / \mu \mathrm{l}, \mathrm{CRP}$ level $\geq 9.9 \mathrm{mg} / \mathrm{dl}$, US thickening of the gallbladder wall, and US pericholecystic fluid were significantly associated to severe acute cholecystitis (Table 3).
The multivariate approach has been developed through a stepwise multivariate logistic regression analysis. Results showed that $\mathrm{WBC}$ count $\geq 12.4 \times 103 / \mu \mathrm{l}$ (OR 5.559; $95 \%$
Table 2 Baseline characteristics, pre-operative signs, and preoperative imaging findings of patients in the derivation cohort according to the final pathology report

\begin{tabular}{|c|c|c|c|}
\hline & $\begin{array}{l}\text { Non-severe acute cholecystitis } \\
\text { group }(N=179)\end{array}$ & $\begin{array}{l}\text { Severe acute cholecystitis } \\
\text { group }(N=116)\end{array}$ & $p$ \\
\hline Gender $[N(\%)]$ & & & 0.006 \\
\hline Male & $74(41.3)$ & $67(57.8)$ & \\
\hline Female & $105(58.7)$ & $49(42.2)$ & \\
\hline Age (years) & $61(43-77)$ & $72(64-80)$ & $<0.001$ \\
\hline Diabetes $[N(\%)]$ & $15(8.4)$ & $26(22.4)$ & 0.001 \\
\hline \multicolumn{4}{|l|}{$\begin{array}{l}\text { Pre-operative local signs of } \\
\text { inflammation }\end{array}$} \\
\hline $\begin{array}{l}\text { RUQ mass/pain/tenderness } \\
{[N(\%)]}\end{array}$ & 164 (91.6) & $105(90.5)$ & 0.834 \\
\hline Murphy's sign $[N(\%)]$ & $97(54.2)$ & $64(55.7)$ & 0.812 \\
\hline \multicolumn{4}{|l|}{$\begin{array}{l}\text { Pre-operative systemic signs of } \\
\text { inflammation }\end{array}$} \\
\hline Temperature $\geq 38{ }^{\circ} \mathrm{C}[N(\%)]$ & $10(5.6)$ & $22(19.0)$ & $<0.001$ \\
\hline $\begin{array}{l}\text { Pre-operative total WBC count } \\
\quad(\times 103 / \mu \mathrm{l})\end{array}$ & $9.3(7.5-12.4)$ & $14.4(11.6-17.5)$ & $<0.001$ \\
\hline $\begin{array}{l}\text { Pre-operative neutrophils count } \\
\quad(\times 103 / \mu \mathrm{l})\end{array}$ & $6.5(4.9-9.9)$ & $11.6(9.0-15.0)$ & $<0.001$ \\
\hline $\begin{array}{l}\text { Pre-operative CRP level } \\
\quad(\mathrm{mg} / \mathrm{dl})\end{array}$ & $1.2(0.5-5.0)$ & $13.7(2.3-23.7)$ & $<0.001$ \\
\hline \multicolumn{4}{|l|}{$\begin{array}{l}\text { Pre-operative abdominal } \\
\text { ultrasound }\end{array}$} \\
\hline $\begin{array}{l}\text { Thickening of the gallbladder } \\
\text { wall }[N(\%)]\end{array}$ & $102(57.0)$ & $87(75.0)$ & 0.002 \\
\hline Pericholecystic fluid $[N(\%)]$ & $22(12.3)$ & $30(25.9)$ & 0.005 \\
\hline $\begin{array}{l}\text { Gallbladder enlargement } \\
\quad[N(\%)]\end{array}$ & $126(70.4)$ & $91(78.4)$ & 0.138 \\
\hline Gallbladder stones $[N(\%)]$ & $163(91.1)$ & $104(89.7)$ & 0.689 \\
\hline
\end{tabular}

$W B C$ white blood cell, $C R P$ C-reactive protein 
a

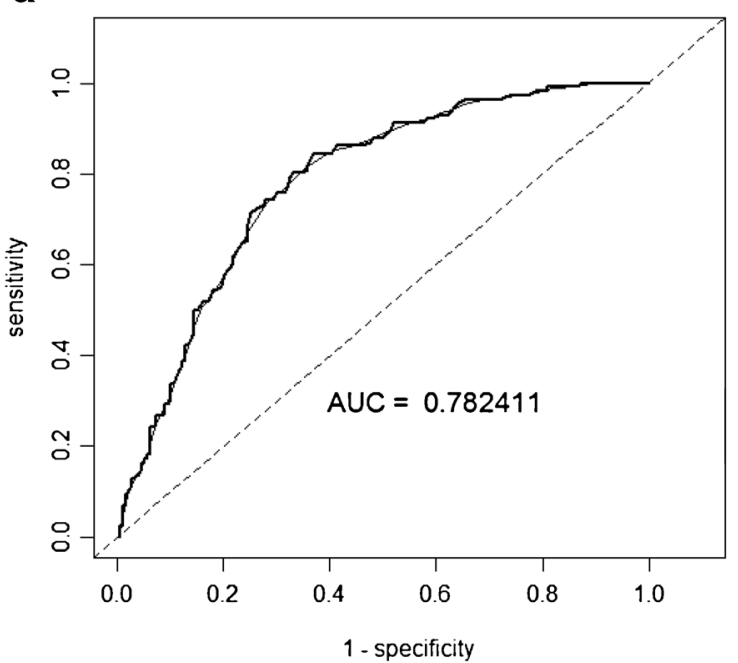

b

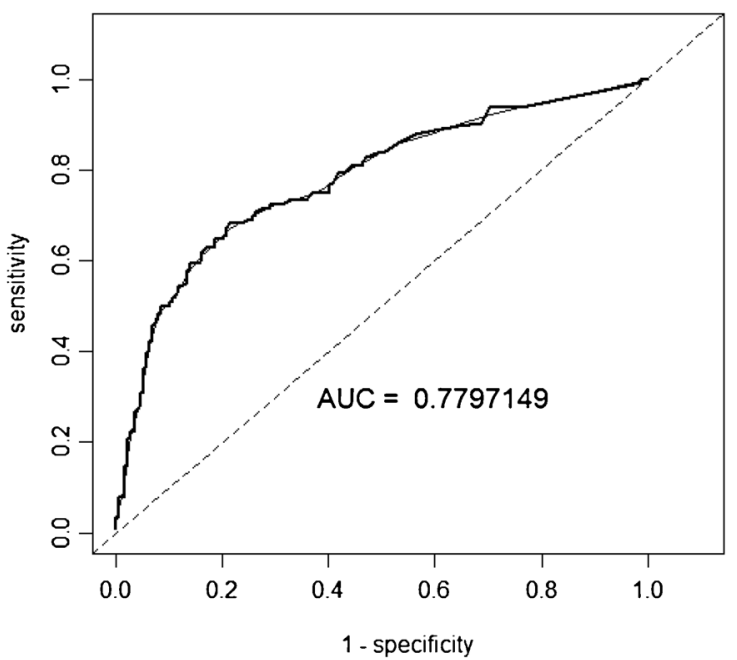

Fig. 1 ROC curves in the derivation cohort showed white blood cell (WBC) count (a) and C-reactive protein (CRP) level (b), as a single predictor of severe acute cholecystitis

CI 3.050-10.130), presence of US thickening of the gallbladder wall (OR 2.109; 95\% CI 1.097-4.053), age as a continuous variable, and CRP level $\geq 9.9 \mathrm{mg} / \mathrm{dl}$ were significantly associated with severe acute cholecystitis in the final pathology report. Furthermore, a significant interaction between the effect of age and CRP level was found; thus, the ORs for CRP level were not constant over the age value, and the ORs for several increments of age were influenced by the CRP level (Tables 4 and 5). Table 4 shows the estimated ORs for CRP $\geq$ $9.9 \mathrm{mg} / \mathrm{dl}$ versus $\mathrm{CRP}<9.9 \mathrm{mg} / \mathrm{dl}$ with a higher OR for young patients and lower OR for old patients. As shown in Table 5, for CRP $<9.9 \mathrm{mg} / \mathrm{dl}$, the ORs for age increments are increasing and significant, while for CRP $\geq 9.9 \mathrm{mg} / \mathrm{dl}$, the ORs are decreasing and not significant. The presence of this significant statistical interaction has important implications since the relationship between each of the interacting covariates (age and CRP) and the risk of having a severe acute cholecystitis depends on the value of the other interacting predictor (i.e., it is not simply additive).

Summarizing the estimated logit is

$$
\begin{aligned}
\hat{g}(\mathbf{x})= & -5.02489+6.435956 \times C R P+1.71541 \\
& \times W B C+0.040997 \times \text { Age }+0.746232 \\
& \times \text { Thick }-0.06786 \times(C R P \times \text { Age })
\end{aligned}
$$

where all the estimated coefficients resulted significant $(p<0.05)$.

A nomogram was employed and it is shown in Fig. 2a. The model likelihood ratio (LR), which assesses the overall significance of the model, is $125.00(p<0.0001)$ and the goodness of fit test ${ }^{19}$ is $z=0.086(p=0.932)$. Therefore, there is no evidence of lack of fit. ${ }^{24,25}$ The model calibration shows a high agreement between predicted probabilities and observed frequencies of the event of interest (Fig. 2b). The ROC curve for the fitted model shows an AUC $=0.857$ (95\% CI 0.8130.900 ) which indicates that the model has a good discrimination ability.

The overall predictive accuracy of the models applied to the validation cohort, as measured by the area under ROC curve, was 0.6719 (95\% CI 0.5508-0.7931).

\section{Nomogram Application}

In a patient with a suspected acute cholecystitis, a point value is assigned for each variable in the nomogram using the first line, and then each point value is summed to obtain both a total point value and the predicted probability of having a severe acute cholecystitis (Fig. 2a). Due to the interaction between age and CRP, the point value for age in patients with CRP $<9.9 \mathrm{mg} / \mathrm{dl}$ must be calculated with the second line of the nomogram, instead for patients with CRP $\geq 9.9 \mathrm{mg} / \mathrm{dl}$ the third line must be used. Consequently, in patients with CRP $\geq$ $9.9 \mathrm{mg} / \mathrm{dl}$, an age increasing is related to a decreasing in the point value assigned.

Four risk classes were identified on the basis of the estimated probability of having a severe acute cholecystitis [i.e., low risk $(0-0.1)$; intermediate risk $(0.1-0.4)$; high risk $(0.4-0.7)$; very high risk (0.7-1)] which correspond to four ranges of nomogram total points [i.e., (0-42); (43-73); (74-95); $(\geq$ 96)]. Furthermore, a cutoff analysis found that the cutoff which maximizes both sensitivity and specificity in predicting severe acute cholecystitis corresponded to a nomogram total point of 74 [sensitivity $=78.5 \%$, specificity $=78.2 \%$, accuracy $=$ $78.3 \%$, positive predictive value $(\mathrm{PPV})=70 \%$, negative predictive value $(\mathrm{NPV})=84.8 \%$ ]. As shown in Fig. 3 , the rate of 
Table 3 Association between baseline characteristics, local and systemic signs of inflammation, and abdominal ultrasound findings and severe acute cholecystitis according to univariate logistic regression model employed in the derivation cohort

\begin{tabular}{|c|c|c|c|}
\hline & \multicolumn{3}{|c|}{ Severe acute cholecystitis } \\
\hline & \multicolumn{3}{|c|}{ Univariate analysis } \\
\hline & Odds ratio & $95 \%$ confidence interval & $p$ \\
\hline \multicolumn{4}{|l|}{ Patients' characteristics } \\
\hline Male & 1.940 & $1.208-3.115$ & 0.006 \\
\hline Age (per year) & 1.044 & $1.027-1.062$ & $<0.001$ \\
\hline $\begin{array}{l}\text { Presence } \\
\text { Local signs of inflammation } \\
\text { Murphy's sign (ref, absence) }\end{array}$ & 3.159 & $1.591-6.269$ & 0.001 \\
\hline $\begin{array}{l}\text { Presence } \\
\text { RUQ mass/pain/tenderness (ref, absence) }\end{array}$ & 1.061 & $0.662-1.699$ & 0.806 \\
\hline $\begin{array}{l}\text { Presence } \\
\text { Systemic signs of inflammation } \\
\left.\text { Temperature (ref, }<38^{\circ} \mathrm{C}\right)\end{array}$ & 0.873 & $0.386-1.974$ & 0.744 \\
\hline $\begin{array}{l}\geq 38^{\circ} \mathrm{C} \\
\text { Pre-operative total WBC count (ref, }<12.4 \times 103 / \mu \mathrm{u})\end{array}$ & 3.956 & $1.797-8.701$ & $<0.001$ \\
\hline $\begin{array}{l}\geq 12.4 \times 103 / \mu \mathrm{l} \\
\text { Pre-operative CRP level }(\mathrm{ref},<9.9 \mathrm{mg} / \mathrm{dl})\end{array}$ & 7.490 & $4.426-12.674$ & $<0.001$ \\
\hline $\begin{array}{l}\geq 9.9 \mathrm{mg} / \mathrm{dl} \\
\text { Abdominal ultrasound findings characteristic } \\
\text { of acute cholecystitis }\end{array}$ & 9.043 & $5.155-15.866$ & $<0.001$ \\
\hline Thickening of the gallbladder wall (ref, absence) & & & \\
\hline $\begin{array}{l}\text { Presence } \\
\text { Pericholecystic fluid (ref, absence) }\end{array}$ & 2.265 & $1.355-3.786$ & 0.002 \\
\hline $\begin{array}{l}\text { Presence } \\
\text { Gallbladder enlargement (ref, absence) }\end{array}$ & 2.489 & $1.353-4.580$ & 0.003 \\
\hline $\begin{array}{l}\text { Presence } \\
\text { Gallbladder stones (ref, absence) }\end{array}$ & 1.531 & $0.886-2.645$ & 0.127 \\
\hline Presence & 0.851 & $0.387-1.870$ & 0.688 \\
\hline
\end{tabular}

$W B C$ white blood cell, $C R P$ C-reactive protein a severe acute cholecystitis in the derivation and validation cohorts increases significantly according to the risk score stratification (Cochran-Armitage trending test for derivation cohort $p<0.0001$, and for validation cohort $p<0.02$ ).

Table 4 Estimated odds ratios and 95\% confidence intervals for CRP $\geq$ $9.9 \mathrm{mg} / \mathrm{dl}$ versus $\mathrm{CRP}<9.9 \mathrm{mg} / \mathrm{dl}$ for several values of age

\begin{tabular}{lllr}
\hline Age (years) & Estimated odds ratio & \multicolumn{2}{c}{$95 \%$ confidence interval } \\
\hline 30 & 81.46467 & 9.1362 & 726.3946 \\
35 & 58.02487 & 8.2533 & 407.9453 \\
40 & 41.32939 & 7.4301 & 229.8928 \\
45 & 29.4377 & 6.6552 & 130.2116 \\
50 & 20.9676 & 5.9146 & 74.3313 \\
55 & 14.9346 & 5.1899 & 42.9764 \\
60 & 10.63747 & 4.4550 & 25.3996 \\
65 & 7.576755 & 3.6773 & 15.6113 \\
70 & 5.396698 & 2.8393 & 10.2575 \\
75 & 3.843908 & 1.9997 & 7.3890 \\
80 & 2.737902 & 1.2899 & 5.8114 \\
85 & 1.950126 & 0.7839 & 4.8514 \\
\hline
\end{tabular}

\section{Discussion}

The identification of patients with severe acute cholecystitis (i.e., gangrenous and phlegmonous) may help the acute care surgeon to guarantee the proper timing for the surgical operation during the first evaluation in the emergency setting, and to hasten the treatment in some patients. Previous studies identified some predictive factors of acute gangrenous cholecystitis such as male gender, age older than 45 or 50 years, presence of diabetes and cardiovascular disease, fever, elevation of WBC count, US thickening of the gallbladder wall, US gallbladder enlargement, and US pericholecystic fluid. ${ }^{3,7,9-15}$ However, the results of risk analyses are expressed as ORs, which makes it difficult to apply in the clinical practice of the acute care surgeon. Furthermore, during the clinical evaluation, it is quite difficult to apply the predictive equation for the diagnosis of acute gangrenous cholecystitis proposed by Nguyen et al. ${ }^{11}$ As reported by Borzellino et al., the severe form of acute cholecystitis should include both gangrenous and phlegmonous cholecystitis, due to their severe clinical course. ${ }^{3}$ Nowadays, there are no studies that have developed an easy graphical tool to identify patients with a severe acute cholecystitis. In the current study, age as a continuous 
Table 5 Estimated odds ratios and $95 \%$ confidence intervals for several increments of age according to CRP $\geq 9.9 \mathrm{mg} / \mathrm{dl}$ and $\mathrm{CRP}<9.9 \mathrm{mg} / \mathrm{dl}$

Fig. 2 Nomogram to predict the probability of severe acute cholecystitis (a) and the calibration plot (b)

\begin{tabular}{llllll}
\hline & \multicolumn{2}{l}{$\mathrm{CRP}<9.9 \mathrm{mg} / \mathrm{dl}$} & & \multicolumn{2}{l}{$\mathrm{CRP} \geq 9.9 \mathrm{mg} / \mathrm{dl}$} \\
\cline { 2 - 3 } \cline { 5 - 6 } Increments of age (years) & Odds ratio & $95 \%$ confidence interval & & Odds ratio & $95 \%$ confidence interval \\
\hline 5 & 1.04185 & $1.01727-1.06703$ & & 0.97349 & $0.93177-1.01709$ \\
10 & 1.22751 & $1.08937-1.38316$ & & 0.87432 & $0.70233-1.08842$ \\
15 & 1.50677 & $1.18672-1.91314$ & & 0.76443 & $0.49326-1.18466$ \\
20 & 1.84957 & $1.29277-2.64618$ & & 0.66835 & $0.34643-1.28942$ \\
25 & 2.27036 & $1.40830-3.66010$ & & 0.58435 & $0.24331-1.40343$ \\
30 & 3.42091 & $1.67126-7.00227$ & & 0.44669 & $0.12001-1.66259$ \\
\hline
\end{tabular}

a

\begin{tabular}{|c|c|c|c|c|c|c|c|c|c|c|c|}
\hline & 0 & 10 & 20 & 30 & 40 & 50 & 60 & 70 & 80 & 90 & 100 \\
\hline
\end{tabular}

Age (CRP $<9.9 \mathrm{mg} / \mathrm{dl})$

Age (CRP $\geq 9.9 \mathrm{mg} / \mathrm{dl}$ )

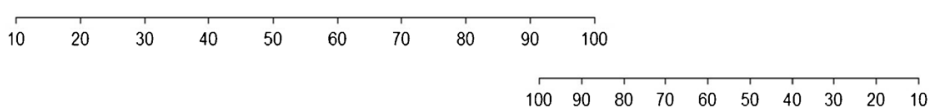

WBC count $\geq 12.4 \times 10^{3} / \mu \mathrm{l}$

YES

US Thickening of the gallbladder wall

Total points

Predicted probability of severe acute cholecystitis
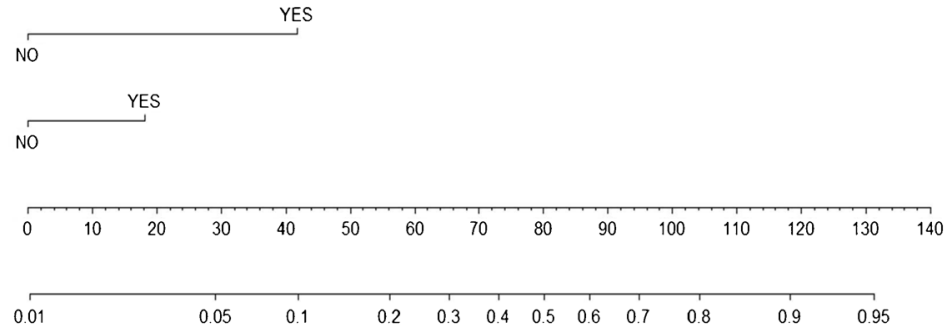

b

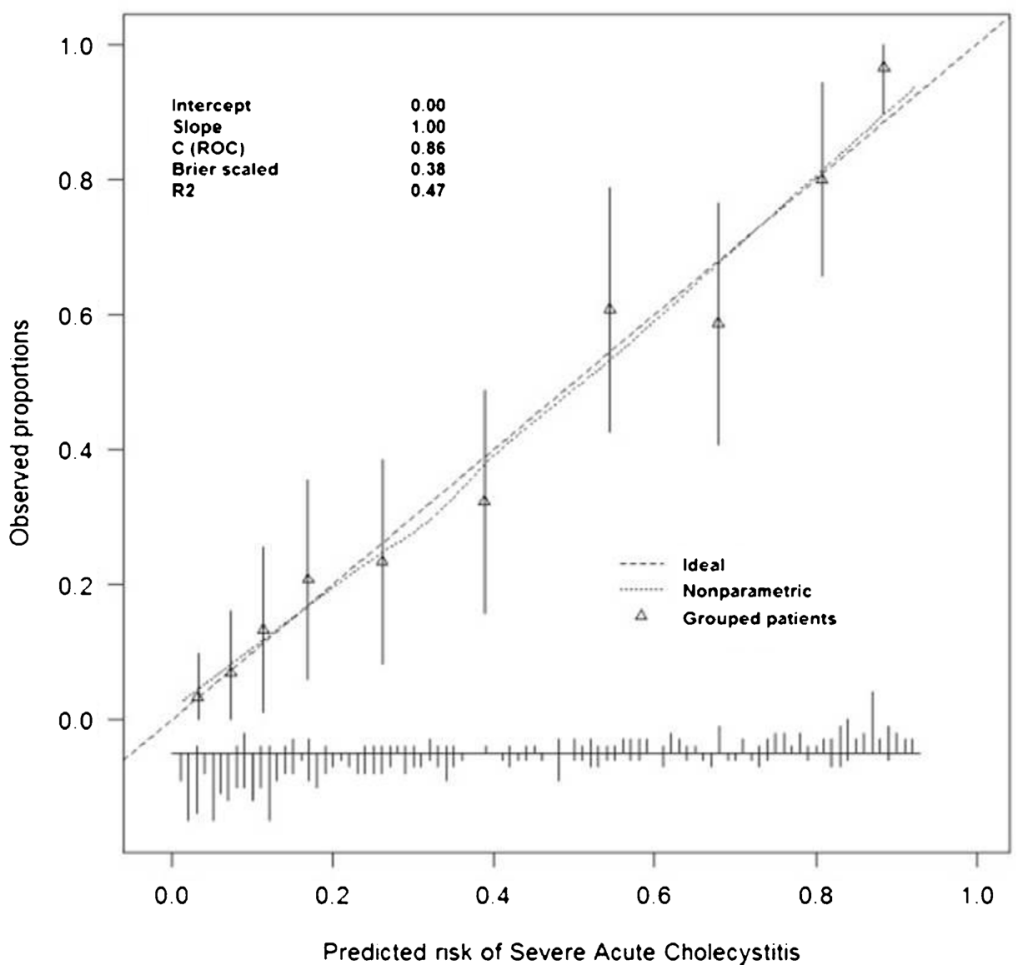


Fig. 3 Observed percentage of patients with severe acute cholecystitis according to the nomogram total point and the risk score stratification in the derivation and validation cohorts (Cochran-Armitage trending test for derivation cohort $p<0.0001$, and for validation cohort $p<0.02$ )

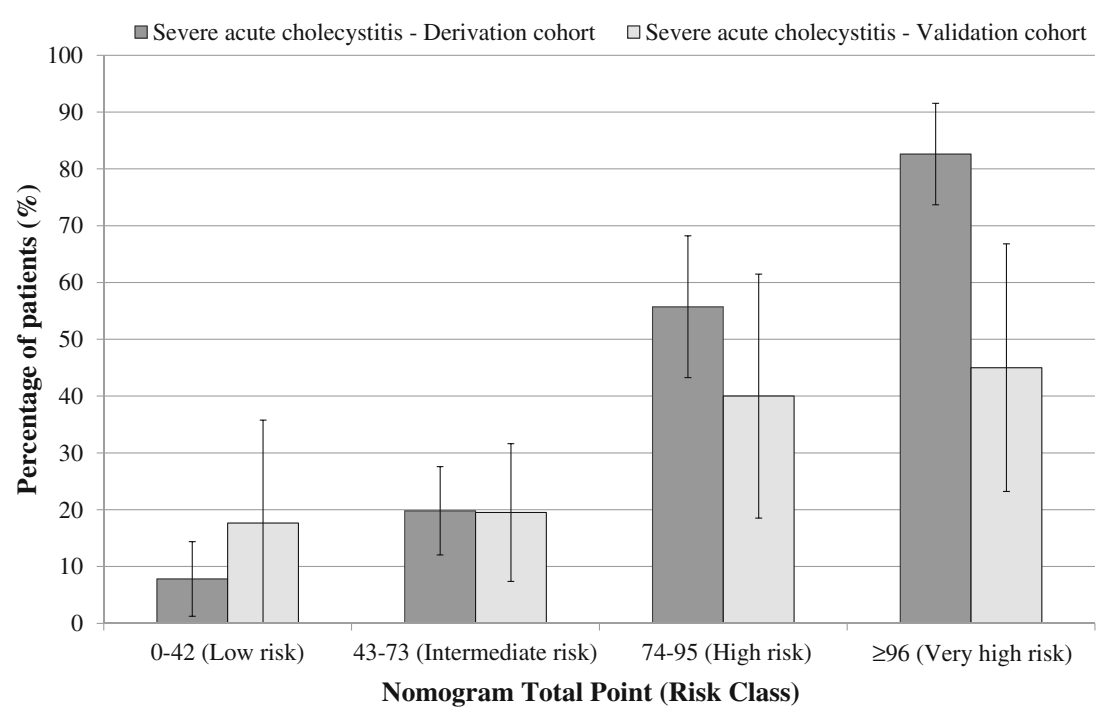

variable, WBC count $\geq 12.4 \times 103 / \mu \mathrm{l}, \mathrm{CRP}$ level $\geq 9.9 \mathrm{mg} / \mathrm{dl}$, and presence of thickening of the gallbladder wall in the abdominal US evaluation were significantly associated with severe acute cholecystitis (i.e., gangrenous and phlegmonous) at final pathology report. Furthermore, it has been shown that the levels of CRP increase with age, ${ }^{26}$ and this interaction may be supported by the fact that younger age reflects fewer chronic conditions and better physical health, with a consequent lower chronic systemic inflammation. In this study, an interaction between age and CRP level has been found; thus, a CRP level $\geq 9.9 \mathrm{mg} / \mathrm{dl}$ in young patients reflects a higher risk of severe acute inflammation of the gallbladder compared to older patients (Table 4). Based on these findings and using four information readily available during the evaluation of the patients, we have developed an easy graphical tool (i.e., nomogram - Fig. 2a) with a good discrimination ability (AUC $=0.857$ ) to help the acute care surgeon to identify patients with severe acute cholecystitis who might be addressed to an earlier surgical operation, supported by the fact that gangrenous and phlegmonous cholecystitis were considered more life-threatening conditions than edematous cholecystitis. ${ }^{3}$ It is clear that, in patients with acute gangrenous and phlegmonous cholecystitis, the best schedule for such a difficult cholecystectomy is the first case in the morning when the team is fresh and ready to deal a challenging operation; however, these two pathologies have the potential to evolve to more serious conditions with a systemic organ dysfunction if surgery is delayed. Thus, according to the nomogram evaluation, patients with a total point $\geq 74$ (sensitivity $=78.5 \%$, specificity $=78.2 \%$, accuracy $=78.3 \%$, PPV $=70 \%$, NPV $=$ $84.8 \%$ ) are classified by the model with a high risk of severe acute cholecystitis and they may be considered for surgical operation to reduce the possible risk of progression of the disease process such as intraluminal hemorrhage, perforation, abscess formation, septic shock, and multiple organ dysfunction. On the other hand, in patients with a total point $\leq 73$ (low or intermediate risk of severe acute cholecystitis), the surgical operation may be deferred or avoided by giving priority to patients with more severe pathologies.

\section{Limitations of the Study}

This study has some limitations which have to be pointed out. Firstly, this is a retrospective study in which 123 patients were excluded because the CRP or the abdominal US were not performed during the first evaluation in the emergency or medical departments, and a selection bias may occur. However, in spite of the retrospective nature of the study, the data collected from the hospital electronic medical records of the remaining 393 patients were incorporated in the electronic records prospectively during the hospital stay of the patients, and this supports the accuracy of the data collection. Secondly, in the validation cohort, there are a low number of patients with severe acute cholecystitis that may influence the predictive accuracy of the model applied to the validation cohort of patients. However, the Cochran-Armitage trending test confirms the significant increase in the rate of severe acute cholecystitis according to the risk score stratification in both the derivation and validation cohorts, and this supports the potential role of the nomogram in the clinical practice. Thirdly, this nomogram seems a useful graphical tool to identify patients with severe acute cholecystitis; however due to the study design without control group, it is not possible to evaluate the external validity of the nomogram and its influence on the timing of surgical operation and postoperative outcomes. Thus, this nomogram will be validated in a prospective study with the aims to compare the nomogram risk score stratification with the pathological diagnosis of severe acute cholecystitis, to improve the risk score stratification, to evaluate its correlation with timing of surgical operation, surgical 
approach (i.e., laparoscopy or open cholecystectomy), conversion rate, complications and mortality, and to identify the best nomogram total point cutoff useful to prioritize patients for emergency surgical operations.

Author Contribution Conception and design: Portinari, Occhionorelli, Scagliarini, Valpiani

Acquisition of data: Andreotti, Portinari, Occhionorelli, Stano, Carcoforo

Analysis and interpretation of data: Scagliarini, Bianconcini, Valpiani, Portinari

Drafting the article: Portinari, Scagliarini, Valpiani, Occhionorelli

Critical revision of the article: Carcoforo, Stano, Andreotti, Bianconcini

Final approval of the version: Portinari, Scagliarini, Valpiani, Bianconcini, Andreotti, Stano, Carcoforo, Occhionorelli

Agreement to be accountable for all aspects of the work in ensuring that questions related to the accuracy or integrity of any part of the work are appropriately investigated and resolved: Portinari, Scagliarini, Valpiani, Bianconcini, Andreotti, Stano, Carcoforo, Occhionorelli

\section{Compliance with Ethical Standards}

This study was approved by the Institutional Review Board at the S. Anna University Hospital of Ferrara (Ethical Committee for Human Subject Research study number: 170185). All patients signed a written informed consent. Data collection and analysis were performed in compliance with the Helsinki Declaration of 1975.

Conflict of Interest The authors declare that they have no conflicts of interest.

\section{References}

1. Yamashita Y, Takada T, Strasberg SM, Pitt HA, Gouma DJ, Garden OJ, Buchler MW, Gomi H, Dervenis C, Windsor JA, Kim SW, de Santibanes E, Padbury R, Chen XP, Chan AC, Fan ST, Jagannath P, Mayumi T, Yoshida M, Miura F, Tsuyuguchi T, Itoi T, Supe AN (2013) TG13 surgical management of acute cholecystitis. Journal of hepato-biliary-pancreatic sciences 20 (1):89-96. https://doi.org/10. 1007/s00534-012-0567-x

2. Cao AM, Eslick GD, Cox MR (2016) Early laparoscopic cholecystectomy is superior to delayed acute cholecystitis: a meta-analysis of case-control studies. Surgical endoscopy 30 (3):1172-1182. https://doi.org/10.1007/s00464-015-4325-4

3. Borzellino G, Steccanella F, Mantovani W, Genna M (2013) Predictive factors for the diagnosis of severe acute cholecystitis in an emergency setting. Surgical endoscopy 27 (9):3388-3395. https://doi.org/10.1007/s00464-013-2921-8

4. Strasberg SM (2008) Clinical practice. Acute calculous cholecystitis. The New England journal of medicine 358 (26):2804-2811. https://doi.org/10.1056/NEJMcp0800929

5. Gruber PJ, Silverman RA, Gottesfeld S, Flaster E (1996) Presence of fever and leukocytosis in acute cholecystitis. Annals of emergency medicine 28 (3):273-277

6. Juvonen T, Kiviniemi H, Niemela O, Kairaluoma MI (1992) Diagnostic accuracy of ultrasonography and $\mathrm{C}$ reactive protein concentration in acute cholecystitis: a prospective clinical study. The European journal of surgery $=$ Acta chirurgica 158 (6-7):365-369

7. Yacoub WN, Petrosyan M, Sehgal I, Ma Y, Chandrasoma P, Mason RJ (2010) Prediction of patients with acute cholecystitis requiring emergent cholecystectomy: a simple score. Gastroenterology research and practice 2010:901739. https://doi.org/10.1155/2010/ 901739

8. Yokoe M, Takada T, Strasberg SM, Solomkin JS, Mayumi T, Gomi H, Pitt HA, Garden OJ, Kiriyama S, Hata J, Gabata T, Yoshida M, Miura F, Okamoto K, Tsuyuguchi T, Itoi T, Yamashita Y, Dervenis C, Chan AC, Lau WY, Supe AN, Belli G, Hilvano SC, Liau KH, Kim MH, Kim SW, Ker CG (2013) TG13 diagnostic criteria and severity grading of acute cholecystitis (with videos). Journal of hepato-biliary-pancreatic sciences 20 (1):35-46. https://doi.org/10. 1007/s00534-012-0568-9

9. Merriam LT, Kanaan SA, Dawes LG, Angelos P, Prystowsky JB, Rege RV, Joehl RJ (1999) Gangrenous cholecystitis: analysis of risk factors and experience with laparoscopic cholecystectomy. Surgery 126 (4):680-685; discussion 685-686

10. Fagan SP, Awad SS, Rahwan K, Hira K, Aoki N, Itani KM, Berger DH (2003) Prognostic factors for the development of gangrenous cholecystitis. American journal of surgery 186 (5):481-485

11. Nguyen L, Fagan SP, Lee TC, Aoki N, Itani KM, Berger DH, Awad SS (2004) Use of a predictive equation for diagnosis of acute gangrenous cholecystitis. American journal of surgery 188 (5):463466. https://doi.org/10.1016/j.amjsurg.2004.07.013

12. Aydin C, Altaca G, Berber I, Tekin K, Kara M, Titiz I (2006) Prognostic parameters for the prediction of acute gangrenous cholecystitis. Journal of hepato-biliary-pancreatic surgery 13 (2):155159. https://doi.org/10.1007/s00534-005-1042-8

13. Cho JY, Han HS, Yoon YS, Ahn KS (2010) Risk factors for acute cholecystitis and a complicated clinical course in patients with symptomatic cholelithiasis. Archives of surgery (Chicago, Ill : 1960) 145 (4):329-333; discussion 333. https://doi.org/10.1001/ archsurg.2010.35

14. Falor AE, Zobel M, Kaji A, Neville A, De Virgilio C (2012) Admission variables predictive of gangrenous cholecystitis. The American surgeon 78 (10):1075-1078

15. Wu B, Buddensick TJ, Ferdosi H, Narducci DM, Sautter A, Setiawan L, Shaukat H, Siddique M, Sulkowski GN, Kamangar F, Kowdley GC, Cunningham SC (2014) Predicting gangrenous cholecystitis. HPB : the official journal of the International Hepato Pancreato Biliary Association 16 (9):801-806. https://doi. org/10.1111/hpb.12226

16. Vandenbroucke JP, von Elm E, Altman DG, Gotzsche PC, Mulrow CD, Pocock SJ, Poole C, Schlesselman JJ, Egger M (2014) Strengthening the Reporting of Observational Studies in Epidemiology (STROBE): explanation and elaboration. International journal of surgery (London, England) 12 (12):1500 1524. https://doi.org/10.1016/j.ijsu.2014.07.014

17. Shakespear JS, Shaaban AM, Rezvani M (2010) CT findings of acute cholecystitis and its complications. AJR American journal of roentgenology 194 (6):1523-1529. https://doi.org/10.2214/ajr. 09.3640

18. Hosmer DW, Hosmer T, Le Cessie S, Lemeshow S (1997) A comparison of goodness-of-fit tests for the logistic regression model. Statistics in medicine 16 (9):965-980

19. Le Cessie S, van Houwelingen JC (1991) A goodness of fit test for binary data based on smooting residuals. Biometrics 47:1267-1282

20. Royston P, Altman DG (2010) Visualizing and assessing discrimination in the logistic regression model. Statistics in medicine 29 (24):2508-2520. https://doi.org/10.1002/sim.3994

21. Steyerberg EW, Vickers AJ, Cook NR, Gerds T, Gonen M, Obuchowski N, Pencina MJ, Kattan MW (2010) Assessing the performance of prediction models: a framework for traditional and novel measures. Epidemiology (Cambridge, Mass) 21 (1): 128-138. https://doi.org/10.1097/EDE.0b013e3181c30fb2 
22. Harrell FEJ (2014) rms: Regression Modeling Strategies. R package version 4.1. http://CRAN.R-project.org/package=rms.

23. Team RDC (2013) R: A Language and Environment for Statistical Computing, R Foundation for Statistical. http://www.R-project. org/.

24. Harrell FEJ (2001) Regression modeling strategies. Springer, New York
25. Agresti A (2002) Categorical data analysis. John Wiley \& Sons, New York

26. Woloshin S, Schwartz LM (2005) Distribution of C-reactive protein values in the United States. The New England journal of medicine 352 (15):1611-1613. https://doi.org/10.1056/ nejm200504143521525 